\title{
The Role of Non-Invasive Ventilation (NIV) In the Era of COVID-19 Pandemic
}

\author{
Ahmed M Abbas ${ }^{1,2 *}$, Mohamed M Abdelkarem ${ }^{2,3}$, Mohamed A Salah ${ }^{2,3}$, Ahmed S Sedik ${ }^{2,3}$, Hossam \\ Aldein Samir ${ }^{2,3}$, Zakria Y Elessemy ${ }^{2,3}$, Emad Zarief Kamel ${ }^{2,4}$ \\ ${ }^{1}$ Department of Obstetrics \& Gynecology, Faculty of Medicine, Assiut University, Egypt \\ ${ }^{2}$ COvid-19 Research of Assiut University Association (CORAUNA) group, Egypt \\ ${ }^{3}$ House-officer, Faculty of Medicine, Assiut University, Egypt \\ ${ }^{4}$ Department of Anesthesia and Critical Care Medicine, Faculty of Medicine, Assiut University, Egypt
}

\begin{abstract}
ABBREVIATIONS: COVID-19: Coronavirus disease-19; ARDS: Acute Respiratory Distress Syndrome; NIV: Non-Invasive Ventilation; WHO: World Health Organization; HFOT: High Flow Nasal Cannula Oxygen Therapy; BIPAP: Bi-Level Positive Airway Pressure; CPAP: Continuous Positive Airway Pressure
\end{abstract}

\section{MINI REVIEW}

With the current emergent situation of Coronavirus disease-19 (COVID-19) pandemic all over the world, the need for ventilators increases every day. About 1-3\% of COVID-19 patients can develop acute respiratory distress syndrome (ARDS) that ranges from mild to severe [1]. So, the shortage of mechanical ventilators is expected to be a critical problem in many countries. Non-invasive ventilation (NIV) may help in the Management of COVID-19 patients. It does not replace invasive mechanical ventilation but can provide a bridge to it [2]. In China, more than $50 \%$ of treated patients required NIV or High Flow Nasal Cannula [3]. However, the World Health Organization (WHO) reported NIV as a high-risk aerosolgenerating procedure, increasing the risk of infection transmission, especially to healthcare providers [4].

Thus, virus aerosolization during non-invasive ventilation should be limited as possible. In this short review, we tried to find the role of NIV in the Management of COVID-19 patients, its indication, limitations, and recommendations.

\section{Indications and Advantages of NIV}

Non-invasive ventilation is recognized as the first-line therapy in acute hypercapnic respiratory failure, and it' could be superior to high flow nasal cannula oxygen therapy (HFOT) in patients with pulmonary hypertension equal to or less than 7.35 [5]. Noninvasive ventilation also seems to be more efficient than standard oxygen using a valve-bag mask to prevent profound oxygen desaturation. Using NIV can help patients to avoid the hazards of endotracheal intubation e.g., airway instrumentation and its sequalae, hemodynamic collapse, cardiac arrest, and aspiration [6].

In COVID-19, bi-level positive airway pressure (BIPAP) mainly used for hypercapnic respiratory failure patients, while Continuous positive airway pressure (CPAP) is sufficient for hypoxemic patients [2]. There are many other some situations where NIV can offer help e.g. acute asthmatic attack, bronchitis, pneumonia, acute congestive heart failure with pulmonary edema, neurovascular disorders, acute lung injury, and cystic fibrosis.
Quick Response Code:

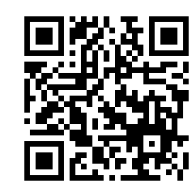

Address for correspondence: Ahmed M. Abbas, MD, Professor at Department of Obstetrics and Gynecology, Women Health Hospital, Assiut University, Egypt

Received: June 12, 2020 Published: July 10, 2020

How to cite this article: Ahmed MA, Mohamed MA, Mohamed AS, Ahmed SS, Hossam AS, Zakria YE, Emad Zarief K. The Role of Non-Invasive Ventilation (NIV) In the Era of COVID-19 Pandemic. 2020 - 2(4) OAJBS.ID.000188. DOI: 10.38125/OAJBS.000188 


\section{Limitations of Non-Invasive Ventilation}

Although a lot of advantages of NIV and uses, it has its own disadvantages and limitations to use in patients as it is not suitable for: respiratory arrested patients, who are hemodynamically unstable, who has a multiorgan failure, who has upper airway surgery, a diminished excessive tracheal secretions. uncooperative or agitated patients, and situations where conscious level is decreased [7]. The most popular disadvantage of NIV is leakage. We cannot know how much to reach to the patient, and common ways to calculate leakage are unreliable. This leakage may lead to dry eyes and conjunctivitis. Increasing the risk of aspirations and gastric dilations are remarkable risks of NIV [8].

There are other significant complications caused by NIV include aspiration pneumonia in $5 \%$ of patients, hypotension, and pneumothorax [8]. Due to the lack of efficacy and risk of infection in NIV, patient with COVID-19 is not recommended to be treated with NIV [2]. Given the above, we can consider any patient who has the risk of these conditions is completely or relatively contraindicated to use NIV.

\section{Recommendations for Using Non-Invasive Ventilators}

Non-invasive ventilation can play plays vital role in managing hospitalized COVID-19 patients. It is the first choice in $41.6 \%$ of admitted patients [3]. There are high recommendations to start oxygen therapy in respiratory failure patients with mild to severe hypoxia by initial flow $5 \mathrm{~L} / \mathrm{min}$ to reach target saturation (adult SpO2 $\geq 90 \%$, pregnant Sp02 92-95\%, children's SpO2 $\geq 90 \%$, and in children with additional concomitant airway obstruction, apnea, respiratory failure, central cyanosis). In 2003, Cheung et al. [9] collected data of patients who had SARS related respiratory failure showed that NIV had decreased the incidence of intubation and it is complications by $70 \%$. However, there are many studies that deny effectiveness of NIV comparing with invasive ventilation in ICU. There are two explanations: firstly, increase intubation rate due to the severity of hypoxia, second, most patients who need NIV managed outside ICU.

NIV is ineffective in respiratory failure COVID-19 patients who are associated with comorbid conditions. Using NIV is not a routine in patients with hypercapnia (acute exacerbation of chronic obstructive pulmonary disease, cardiogenic pulmonary edema), hemodynamic instability, and abnormal mental status especially if there's no improvement or worsening in respiratory failure in one hour after using NIV [9]. Patients in late-stage respiratory failure and multiorgan failure will not benefit from NIV, and they should have invasive ventilation directly. In a prospective study, NIV showed high failure rate of $85 \%$ and patients are converted to invasive ventilation and the 90 days mortality days were higher in the NIV patients who were converted to invasive ventilation [10]. Based on that evidence, we recommend not using NIV in late-stage respiratory failure patients who have a multiorgan failure, shock, and severe respiratory acidosis.

\section{REFERENCES}

1. Wu Z, McGoogan JM (2020) Characteristics of and important lessons from the coronavirus disease 2019 (COVID-19) outbreak in China: summary of a report of 72314 cases from the Chinese Center for Disease Control and Prevention. JAMA 323(13): 1239-1242.

2. NHS B (2020) Guidance for the role and use of non-invasive respiratory support in adult patients with coronavirus (confirmed or suspected). Version 2: 1559.

3. Guan W, Ni Z, Hu Y, Liang W, Ou C, et al. (2020) Clinical Characteristics of Coronavirus Disease 2019 in China. N Engl J Med 382: 1708-1720.

4. World Health Organization (2020) Rational use of personal protective equipment for coronavirus disease ("COVID-19)" " and considerations during severe shortages: interim guidance. World Health Organization.

5. Frat JP, Joly F, Thille AW (2019) Non-invasive ventilation versus oxygen therapy in patients with acute respiratory failure. Curr Opin Anaesthesiol 32(2): 150-155.

6. Jaber S, Amraoui J, Lefrant JY, Arich C, Cohendy R, et al. (2006) Clinical practice, and risk factors for immediate complications of endotracheal intubation in the intensive care unit: A prospective, multiple-center study. Crit Care Med 34(9): 2355-2361.

7. Sluijs A (2013) Noninvasive ventilation; PROs and CONs. Netherlands J Crit Care 17(2): 27-29.

8. Mehta S, Hill NS (2001) Noninvasive Ventilation. Am J Respir Crit Care Med 163(2): 540-577.

9. Cheung TMT, Yam LYC, So LKY, Lau ACW, Poon E, et al. (2004) Effectiveness of non-invasive positive pressure ventilation in the treatment of acute respiratory failure in severe acute respiratory syndrome. Chest 126(3): 845-850.

10. Rodríguez A, Ferri C, Loeches IM, Díaz E, Masclans JR, et al. (2017) Risk factors for non-invasive ventilation failure in critically ill subjects with confirmed influenza infection. Respir Care 62(10): 1307-1315. 